\title{
Characterization of Polymer Behaviour in Microchannels
}

\author{
M. Costa ${ }^{1,3}$, J.Vasco, ${ }^{1,2}$ A. S. Pouzada ${ }^{1,3}$, A. J. Pontes ${ }^{1,3}$ \\ ${ }^{1}$ Institute for Polymer and Composites/I3N, University of Minho, Guimarães, Portugal \\ ${ }^{2}$ Department of Mechanical Engineering, Polytechnic Institute of Leiria, Leiria, Portugal \\ ${ }^{3}$ Department of Polymer Engineering, University of Minho, Guimarães, Portugal
}

\begin{abstract}
Microinjection moulding can be used to process monitoring and rheological characterization can help to understand the behavior of polymer melt flows during the filing of micro cavities. The system used allows a study on characterization of polymer behavior in microchannels.

This approach is appropriate since rheological phenomena such as wall slip, surface tension, melt pressure drop and polymer flow length can be studied. In this system, the data acquisition has made by incorporation of two sensors inside the mould.
\end{abstract}

Keywords: Microinjection moulding, Microchannels, Rheology, Flow.

\section{INTRODUCTION}

Currently, the ascension of microinjection is associated in many micro technologies, such as micro-optics, microfluidic, microelectronics and micro mechanical. A concept of a micro component is associated with a high ratio of surface area and volume, such as the lateral walls of the microchannels and part to replicate with reduced dimensions [1], the presence of a high ratio of appearance, the weight of the part [2], as well as the detail of the microstructures with micrometric dimensions [3]. Microinjection mounding, $(\mu \mathrm{I})$ is one of the main technologies for micro fabrication and micro replication, this technology has to be studied systematically, in order to determine the limitations of the process. Some of these limitations is understand what happens to the micro flow of a molten polymer in microchannel.

In the presence of microchannels it was associated one raised reason of surface and volume, that in microchannel it can be generate a fast cooling. It appears the importance of the range window of mould temperature and melts temperatures of the polymers. Several studies has been disclosed that the increase of the temperature of the cylinder and the mold as well as an increase of the injection speed provides that the melt polymer has better capacity to fill the final part [4]. Macroscopically the values obtained to indicate the models flow imposed to forward flow of the molten polymer, are not appropriate to characterize the flow at the micro scale.

Rheological characterization of polymers melts is widely used in process monitoring, quality control, process design and simulation, and troubleshooting applications [5]. Generally, instrumentation based on rotation, capillary or slit flow is used to obtain accurate measurements at a series of set strain rates and temperatures [6]. Some works has been done by using slit/capillary dies embedded into either nozzles or moulds to test the material rheology with an injection moulding machine or extruder [7].

The concept of wall slip was first addressed by Mooney (1931), who found that certain flow curves depended on the radius of the capillary once the shear stress exceeded a critical value [8] .The effect takes place when the shear stress at the microchannel wall exceeds a critical value, typically, above $0.1 \mathrm{MPa}[7,6]$.When wall slip occurs at a critical wall shear stress value the flow curves (wall shear stress versus apparent shear rate) diverge from each other and become defendant on channel dimensions. Usually the boundary conditions at the wall are known and their influence on the flow behavior close to the wall is relevant [9].

Yao et al. [9], studied the effect of viscosity through the slip on the wall, as the surface tension during the filling and verified that the slip should only be considered for channels less than $10 \mu \mathrm{m}$. On the surface tension, the authors mentioned that when it comes to the process of not only this is irrelevant, and in relation to heating by action viscous and insignificant for channels smaller than $100 \mu \mathrm{m}$. Chien et al. [10] have proven that the viscosity over the microchannels is lower than the viscosity measured using a traditional capillary rheometer, also demonstrated that the speed of slip of polymer melts increases with the decrease of the micro channel card, as well as a reduction in the apparent viscosity to canals with lesser dimensions . Vasco et al [11] demonstrated that the temperature of mold is more less than melting temperature of polymer, was observed that the heat transfer analyzed in conventional injection molding does not apply the microinjection, consequence of the presence of high ration reason between surface and volume. Many others researchers studied, Yao et Kim [12], Zao et al. [13], Shen et al. [14], the main conclusions of these studies had been that for high temperatures of casting and the mold the allies to one raised speed injection, observed a positive effect in the flow of polymer. 


\section{EXPERIMENTAL}

\section{Rheometry on Microchannels}

The microchannels were mainly designed for rheological evaluation of polymer flow, therefore, the products of the injection tests with these moulding blocks will provide only useful information on pressure drop along the microchannel, injection pressure and melt front speed. The mould structure consists of standard mould components from HASCO series $\mathrm{K}$, plate dimensions of $130 \times 100 \mathrm{~mm}$, as shown in Figure 1. The cavity plate thickness can accommodate a variety of moulding blocks. Furthermore, this plate is intended to support the data acquisition system, namely the pressure sensors, as show in Figure 2.

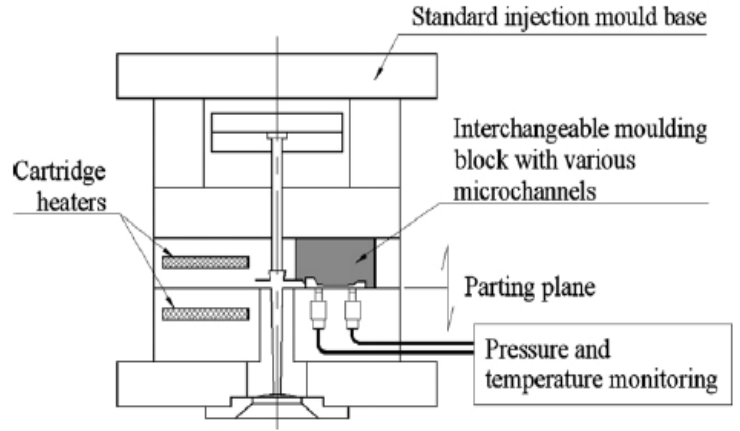

FIGURE 1 - Concept of a tool for rheometric studies in microchannels [11].

\section{Layout in microchannel}

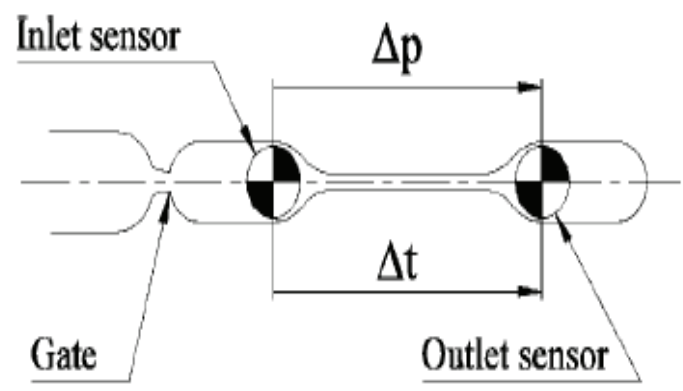

FIGURE 2 - Variables for the rheological assessment of the flow in microchannels. $\Delta p$ - pressure drop; $\Delta t$ - time interval [11].

\section{Microchannel}

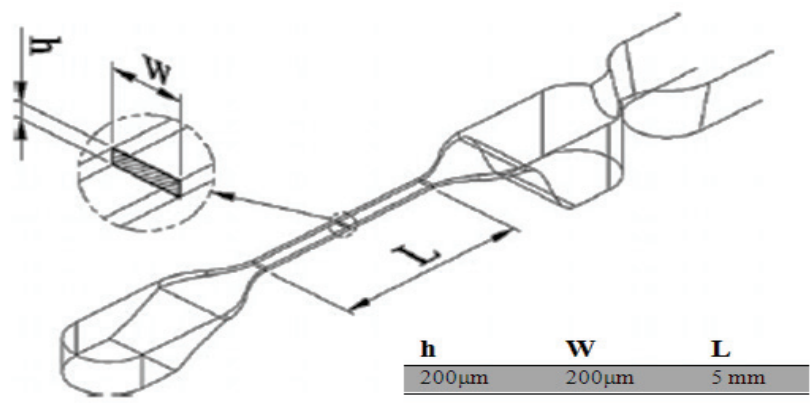

FIGURE 3 - Variables for the rheological assessment of the flow in microchannels. $\Delta p$ - pressure drop; $\Delta t$ - time interval time interval [11].

The purpose of this microchannel, Figure 3, its geometry consists basically on a channel with two pressurerelieving zones on the extremities. Figure 4 show general views of the microchannel. On the gate side, the depth of this relief is higher to enable the full establishment of the flow within the microchannel. On the microchannel itself, it is intended a full established flow that will produces a pressure drop suitable for polymer viscosity evaluation. On the exit side, there is another relief zone where pressure is intended to be as low as possible.
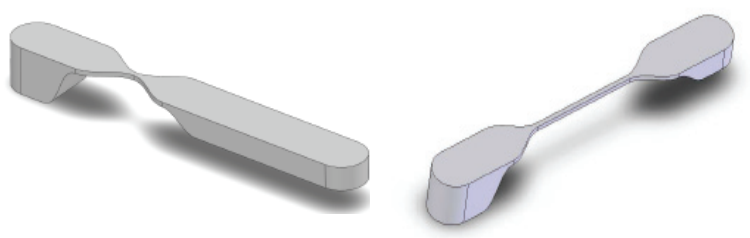

FIGURE 4 - Zero length microchannels $200 \mu \times 200 \mu \mu \mathrm{m}$ (on the left) and microchannel $200 \mu \times 200 \mu$ (on the right) [11].

To determine the entry effects on the microchannel for correction purposes on rheological calculations, a second microchannel with zero length have been designed and manufactured. This geometry have the same entry shape of the other microchannel while the remaining geometry was elongated to enable pressure reading at the exact same location of the original microchannel, as show in Figure 4.

\section{Materials}

During this study the thermoplastics used for micro rheometry studies testing are a common commercially available polypropylene and polystyrene, Table 1 .

\begin{tabular}{c||c||c}
\hline \hline Grade & Melt flow index & Density \\
\hline \hline Moplen & $23 \mathrm{~g} / 10 \mathrm{~min}\left(230^{\circ} \mathrm{C}-\right.$ & $0.9 \mathrm{~g} / \mathrm{cm}^{3}$ \\
HP548R & $2.16 \mathrm{Kg})$ & \\
Edistir & $27 \mathrm{~g} / 10 \mathrm{~min}\left(200^{\circ} \mathrm{C}-5 \mathrm{Kg}\right)$ & $1.05 \mathrm{~g} / \mathrm{cm}^{3}$ \\
N1910 & & \\
\hline
\end{tabular}

Table 1 - Materials. 
The use of a microinjection moulding tool for rheometry purposes provided the preparation of flow curve for two materials, polypropylene, and to polystyrene, developed through the imposition of different injections speeds, in the next Table 2 as demonstrated the main processing conditions.

\begin{tabular}{|c|c|c|}
\hline & $\begin{array}{c}\text { Moplen } \\
\text { HP548R }\end{array}$ & Edistir N1910 \\
\hline $\begin{array}{c}\text { Mold } \\
\text { Temperature } \\
\text { Melt }\left(\mathbf{C}^{0}\right)\end{array}$ & 100 & 100 \\
\hline $\begin{array}{c}\text { Injection } \\
\text { speeds } \\
(\mathbf{m m} / \mathbf{s}) \\
\end{array}$ & $\begin{array}{c}120-140-160- \\
180-200\end{array}$ & $\begin{array}{c}120-140-160-180- \\
200\end{array}$ \\
\hline
\end{tabular}

Table 2 - Processing conditions.

\section{RESULTS AND DISCUSSION}

Figures 5 to 8 shows the typical data acquisition of which samples, expressed by inlet sensor and outlet sensor, to the different materials, the results obtained are reasonable because the curves demonstrated the touch in each sensor of the melt polymer. The microchannels used for rheological evaluation of polymer flow; therefore, the products of the injection tests with these moulding blocks with different microchannels will provide only useful information on pressure drop along the microchannel, injection pressure developed and melts front speed.

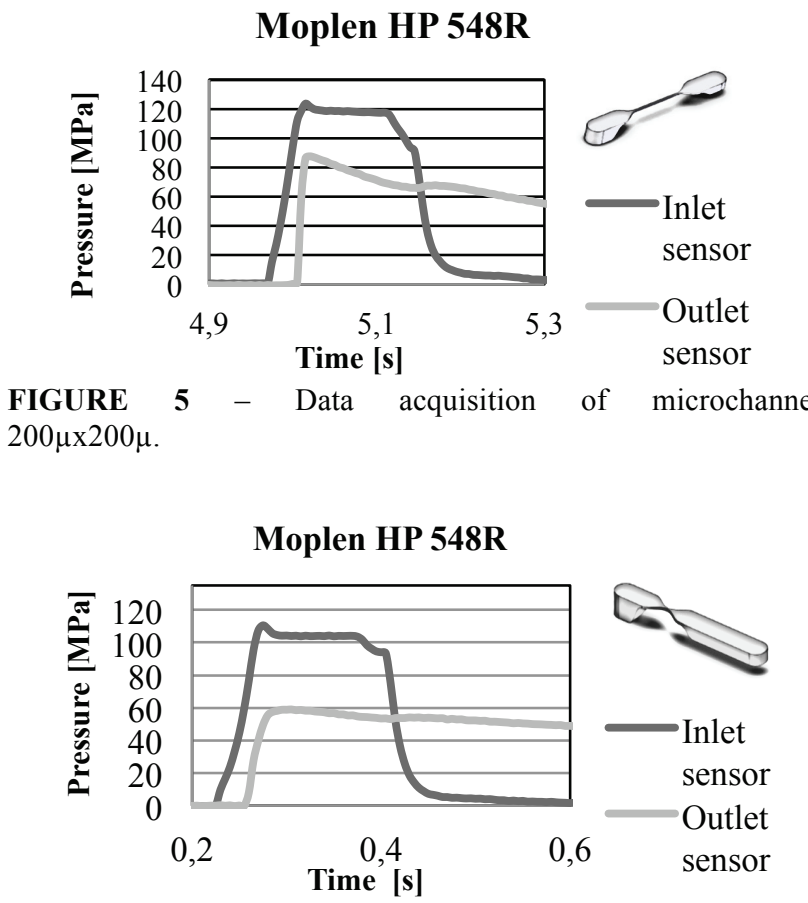

FIGURE 6 - Data acquisition of zero length microchannel $200 \mu \times 200 \mu$.

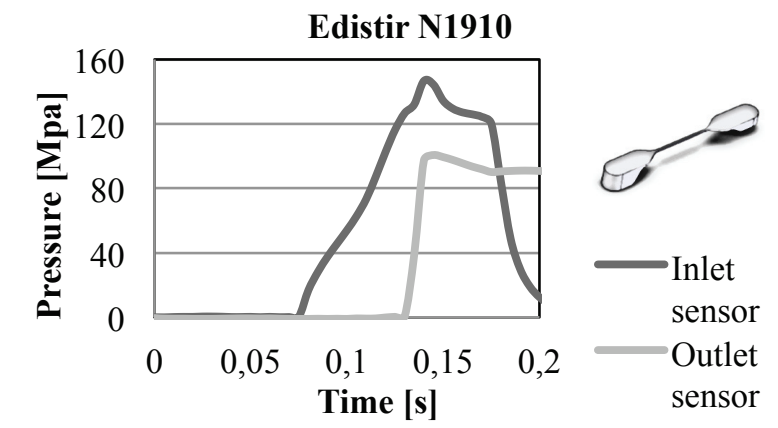

FIGURE 7 - Data acquisition of microchannel $200 \mu \times 200 \mu$.

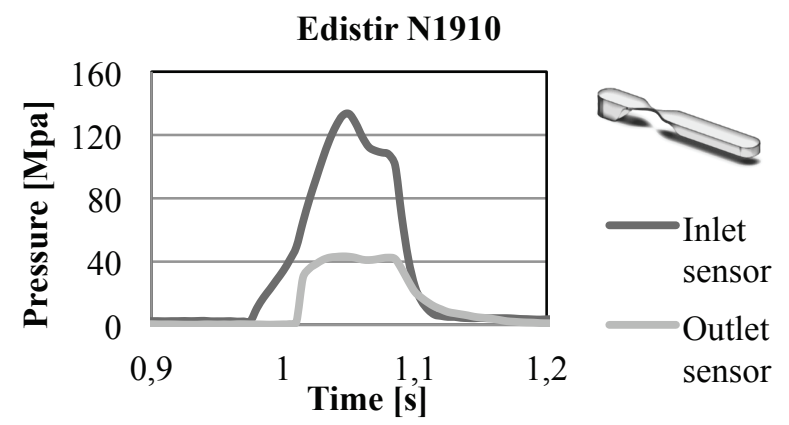

FIGURE 8 - Data acquisition of microchannel, $200 \mu \times 200 \mu$.

In present work both flow curves, Figures 9 and 10, cannot demonstrated the wall-slip effect, however the development flow approaches a region near the slip effect, but cannot demonstrated a fully developed system, since it would probably be necessary to increase the mold temperature and manipulate the processing conditions. In both figures this present high shear rates values, as expected due to the microchannels have a very small aspect ratio. As the magnitude of the shear stresses varies, polymer melts flow in a way that is a superposition of slipping at the wall and shearing within the melt [15].

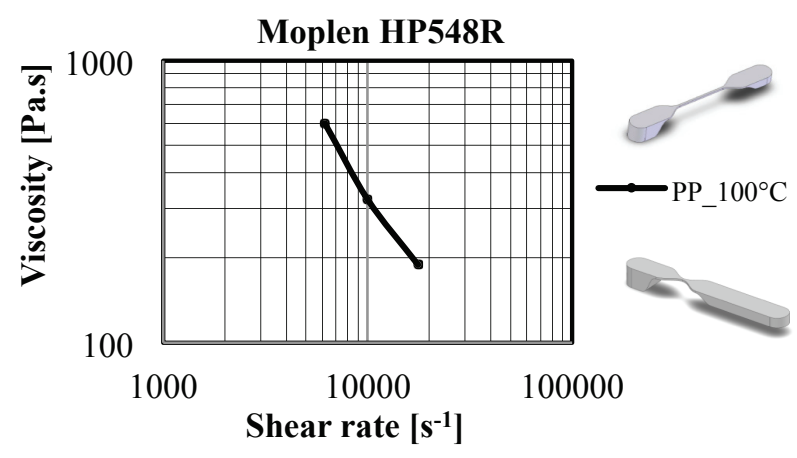

FIGURE 9 - Flow curve obtained at $100{ }^{\circ} \mathrm{C}$ on the mould. 
PS_Edistir N1910

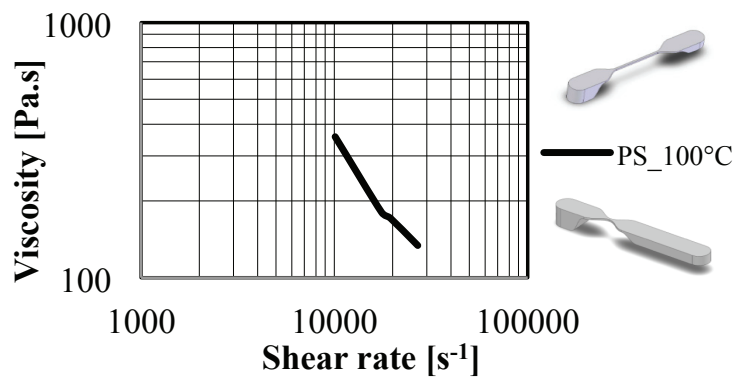

FIGURE 10 - Flow curve obtained at $100{ }^{\circ} \mathrm{C}$ on the mold.

The data gathered initially from the experimental setup enabled important conclusions concerning flow behaviour within both microchannels.

\section{CONCLUSIONS}

An immediate conclusion of this study is that the flow inside the mould is non-isothermal, which means that the data eventually obtained are not to be regarded as quantitatively accurate rheometrical data. As already stated before, the equipment setup in this study is not a microrheometer, but rather a viscometer that replicates the flow conditions in real flow situations, i.e. it is a process analyzer and simulator.

In present work a tool for the quantitative evaluation of the rheological behavior of polymer melts under typical microinjection moulding conditions was developed. The use of a microinjection moulding tool for rheometry purposes provided the establishment of flow curve for polypropylene, (Moplen HP 548R) and to polystyrene, (Edistir N1910). Through the different injections speeds, it is possible observe that the measurement of the pressure drop on a test part shows that wall-slip can also be present on microinjection moulded parts.

\section{ACKNOWLEDGMENTS}

The authors acknowledge the funding support given by ADI through the QREN program in the frame-work of the project Tooling Edge (Project $n .{ }^{\circ}$ 13856).

\section{REFERENCES}

1. Piotter, V., T. Hanemann, R. Ruprecht, and J. Haußelt, Injection molding and related techniques for fabrication of microstructures. Microsystem Technologies, 1997: p. 129-133.

2. Kukla, C., H. Loibl, and H. Detter, MicroInjection Moulding, The aims of a Project Partnership, in Kunstoffe Plastic Europe. 1998. p. 1331-1336

3. Evans, B. and R. Mehalso, How Small is Small A Guide to the New Microfabrication Design and
Process Techniques, in Medical Device \& Diagnostic Industry. 2001.

4. B. Sha, S. Dimov, C. Griffiths, M.S. Packianather, Investigation of micro injection moulding: Factors affecting the replication quality, The Manufacturing Engineering Centre, Cardiff University, Cardiff CF24 3AA, United Kingdom.

5. J.M. Dealy, T.O.Broadhead, Process rheometers for molten plastics: a survey of existing technology, polymer Engineering \& Science 33 (1993) 1513- 1523.

6. A.L.Kelly, T.Gough, B,R.Whiteside, P.D.Coates, High shear strain rate rheometry of polymer melts, journal of applied polymer science 114 (2009) p.864-873.

7. N.Zang, M.D.Gilchist, Characterization of thermo-rheological behavior of polymer melts during the micro injection moulding process.

8. Lee K and Mackley M R 2000. The significance of slip in matching polyethylene processing data with numerical simulation J. Non-Newton. Fluid Mech. 94 159-77.

9. D. Yao, B. Kim, Simulation of the filling process in micro channels for polymeric materials, Journal of Micromechanics and microengineering, 12 (2002) 604-610.

10. R. D. Chien, W.-R. Jong, S.-C. Chen, Study on rheological behavior of polymer melt flowing through micro-channels considering the wallslipeffect, Journal of Micromechanics and Microengineering 15 (2005) 1389-1396.

11. J.C. Vasco, J.M. Maia, A.S. Pouzada, Thermorheological behaviour of polymer melts in microinjection moulding, Journal of Micromechanics and Microengineering 19 (2009) 105012.

12. D.Yao, B. Kim, Scaling issues in miniaturization of injection molded parts,Manuf. Sci. Eng. 126 (2004) 733-739.

13. J. Zhao, R.H. Mayes, G. Chen, H. Xie, P.S. Chan, Effects of process parameters on the micro molding process, Polym. Eng. Sci. 43 (9) (2003) $1542-1554$.

14. Y.K. Shen, S.L. Yeh, S.H. Chen, Threedimensional non-newtonian computations of micro-injection molding with the finite element method, Int. Commun. Heat Mass Transfer 29 (5) (2002) $643-652$.

15. J.C. Vasco, J.M. Maia, A.S. Pouzada Microinjection moulding - Wall- slip evaluation of POM in Microchannels. Proceedings of the Polymer Processing Society 26th Annual Meeting PPS-26, July 4-8, 2010 Banff (Canada). 